\title{
Author Correction: Forging a path to a better normal for conferences and collaboration
}

Vanessa A. Moss (i), Matt Adcock (D), Aidan W. Hotan (D), Rika Kobayashi(D), Glen A. Rees (D), Coralie Siégel(1), Chenoa D. Tremblay (iD and Claire E. Trenham (D)

Correction to: Nature Astronomy https://doi.org/10.1038/s41550-021-01325-z, published online 16 March 2021.

In the version of this article initially published, the articles listed for refs. 15 and 16 were reversed. The articles corresponding to the correct ref. footnotes are shown below.

15. Abbott, A. Nature 577, 13 (2020).

16. How to embrace remote work. Trello https://trello.com/en-AU/remote-work-guide (2021).

The changes have been made to the online version of the article.

Published online: 26 November 2021

https://doi.org/10.1038/s41550-021-01571-1

(๑) Springer Nature Limited 2021 